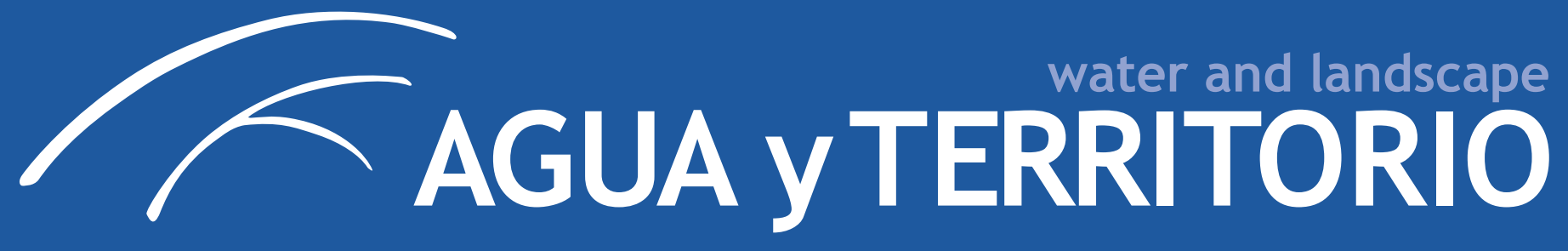

\title{
Cestona en los orígenes del termalismo vasco (1776-1833). La conformación de un establecimiento de baños en Guipúzcoa
}

\author{
Cestona in the origins of Basque thermalism (1776-1833). \\ The establishment of a bathhouse in Guipúzcoa \\ Carlos Larrinaga \\ Universidad de Granada. Granada, España. larrinag67@hotmail.com
}

\begin{abstract}
Resumen - Cestona fue el primer balneario que se creó en el País Vasco y el único, por cierto, que aún hoy en día existe. Pertenece a esa primera generación de casas de baños que se fundaron en España en la segunda mitad del siglo XVIII, en ese deseo de las autoridades de poner en valor las aguas minerales del país. Pues bien, a través de este estudio de caso, pretendemos analizar las dificultades a las que tuvieron que enfrentarse estos balnearios en temas tales como la definición de los derechos de propiedad de las aguas, la inversión de capital, la demanda o la competencia de otros actores en el incipiente mercado de las aguas minerales en España en general y en el País Vasco en particular.

Abstract - Cestona was the first spa that was created in the Basque Country and indeed, the only one that still exists. It belongs to the first generation of bathhouses that were founded in Spain in the second half of the 18th Century in response to the administration's efforts to commercialize the mineral waters of the country. Therefore, through this case study we intend to analyze the difficulties which spas had to face around such issues as the definition of water property rights, capital investment, and the demand or competition from other players in the emerging market of the mineral Waters industry in Spain in general and in the Basque Country in particular.
\end{abstract}

Palabras clave: termalismo; balneario; aguas minerales; derechos de propiedad; inversión de capital; competencia; Cestona; País Vasco; España Keywords: thermalism; spa; mineral waters; property rights; capital investment; competition; Cestona; Basque Country; Spain

Información Artículo: Recibido: 24 mayo 2014 Revisado: 15 julio 2014 Aceptado: 23 septiembre 2014

(c) Universidad de Jaén / Seminario Permanente Agua, Territorio y Medio Ambiente (CSIC) 
Cestona en los orígenes del termalismo vasco (1776-1833). La conformación de un establecimiento de baños en Guipúzcoa

\section{INTRODUCCIÓN ${ }^{1}$}

Al calor del impulso que Carlos III quiso dar al termalismo español en las décadas centrales del siglo XVIII, siguiendo una moda ya plenamente extendida en algunos territorios de Europa, empezaron a surgir en España algunos establecimientos termales no sólo de iniciativa real, sino también particular. Entre estos últimos destacaría el balneario de Cestona, el primero de las provincias vascas y el único de esos balnearios históricos que aún pervive. Pues bien, el objetivo de este trabajo es hacer un estudio de los orígenes de este importante centro termal y su contribución a los inicios del termalismo vasco. Para ello queremos centrarnos en aspectos tan importantes como el derecho de la propiedad y los intereses contrapuestos que se suscitaron en torno a las aguas de Guesalaga a finales del siglo XVIII y principios del XIX; la inversión de capital llevada a cabo inicialmente por su primer propietario, Vicente de Lili, y después por el marqués de San Millán, el verdadero artífice de la puesta en marcha de este establecimiento de renombre; y en la competencia a la que muy pronto tuvo que hacer frente el propio marquesado de San Millán respecto del negocio hotelero en Cestona, en un momento, no hay que olvidarlo, de claro avance del ideario liberal y de la implantación en España de la libertad de negocio, cuando se empezaban a sentar las bases de la industria hostelera en el País Vasco del siglo XIX. Recurriendo a un estudio de caso, el objetivo es analizar los comienzos de la conformación de la oferta termal en el País Vasco.

\section{LA DINASTÍA BORBÓN}

Y LOS COMIENZOS DEL TERMALISMO EN ESPAÑA

En comparación con otras regiones de la Europa occidental, como Spa en Valonia y, sobre todo, Inglaterra, España se incorporó tardíamente al fenómeno balneario. Es cierto que, antes de la llegada de los Borbones al trono español, algunos miembros de la familia real Habsburgo habían tomado las aguas, teniendo constancia del caso de la reina Mariana de Austria en Sacedón (Guadalajara) en el último tercio del siglo XVII², pero no había sido suficiente para consolidar un fenómeno que, en el caso inglés, por ejemplo, estaba ya muy desarrollado para principios del siglo XVII ${ }^{3}$. Buena prueba del atraso que España padecía en este terreno puede rastrearse a través de la literatura de la época. En este sentido, la obra más significativa corresponde a Ildefonso Limón Montero, catedrático en la Universidad de Alcalá de Henares y autor de Espejo cristalino de las aguas de España (1697), en la que denunciaba el estado de abandono en que se encontraban en el país las fuentes de aguas minero-medicinales. A decir verdad, con este trabajo se inauguraba todo un conjunto de obras sobre los baños y las aguas termales en España, las cuales pretendían, por un lado, dar a conocer las fuentes termales existentes y, por otro, denunciar el mal estado en que se encontraban. Sin duda,

1 Una primera versión de este trabajo fue presentada en el XI Congreso de la Asociación Española de Historia Económica, celebrado en Madrid los días 4 y 5 de septiembre de 2014. Este artículo se ha beneficiado del proyecto HAR2011-23214 (Orígenes, consolidación y evolución del turismo en España), financiado por el Ministerio de Economía y Competitividad.

2 Mercado Blanco et al., 2003, 75.

3 Hembry, 1990. el objetivo era el que se tomaran medidas al respecto para tratar de paliar esta situación y poder aprovechar dichos veneros de la misma forma que se estaban ya aprovechando en otras zonas europeas.

En cualquier caso, y pese al cambio de dinastía al doblar la centuria, todavía hubo que esperar un tiempo para sentar las bases del termalismo español y de lo que habrían de ser los orígenes del turismo de salud y bienestar en nuestro país. En efecto, a raíz de toda esa literatura publicada desde finales del XVII y primeras décadas del XVIII', a mediados de ese siglo, el Real Tribunal del Protomedicato trató de poner remedio a esta situación tan calamitosa. Al fin y al cabo, este organismo era la máxima instancia médica de España y, puesto que el uso de las aguas termales estaba íntimamente vinculado a los problemas de salud y enfermedad, no es extraño que el Protomedicato buscara arbitrar algún tipo de solución que pusiera en valor dichas fuentes minero-medicinales. Aunque para ello, evidentemente, era preciso contar con el apoyo de las más superiores instancias del Estado. Y así fue, ya que el ilustrado marqués de la Ensenada, a la sazón secretario del Consejo de Castilla, encargó al prestigioso médico gallego Pedro Gómez de Bedoya la elaboración de una relación de fuentes y baños minerales de toda España. Pues bien, con la colaboración de un buen número de médicos, cirujanos y boticarios, Bedoya escribió su Historia Universal de las Fuentes Minerales de España, la cual, pese a estar inconclusa, sirvió para avivar la preocupación por el estado de las aguas y baños minerales del reino. Preocupación que se vio plasmada en la aparición de nuevos trabajos en el último tercio del siglo XVIII'.

Pues bien, en este novedoso contexto de inquietud por el estado de las fuentes minerales, la Real Sociedad Bascongada de los Amigos del País se ocupó igualmente de las aguas de Guesalaga, en el municipio de Cestona. En concreto, en el artículo III de sus Extractos de 1774, dedicado a la salud pública, hay un epígrafe titulado "Noticia de la fuente termal de Guesalaga en Guipúzcoa". Primeramente se pensó que fue el médico de Cestona Josef Mateo quien identificó este venero y quien así lo hizo saber a la Bascongada ${ }^{6}$. Hoy en día, sin embargo, gracias a las investigaciones de Urquía, se piensa que fue Vicente de Lili, fundador y tesorero de dicha sociedad, quien comunicó el descubrimiento de dicha fuente, habida cuenta, además, de que la misma se encontraba en un castañar perteneciente a su mayorazgo de Lili ${ }^{7}$. Incluso fue él mismo, como se tendrá ocasión de ver, quien inauguró la primera casa de baños aprovechando estas aguas termales de Guesalaga. De esta manera, el País Vasco se sumaba también a esa corriente favorable a la recuperación de las aguas termales del reino. Estaríamos en los primeros balbuceos de la conformación de una primitiva oferta termal.

Sí conviene decir que la inmensa mayoría de los trabajos que se publicaron a lo largo de todo este periodo correspondieron a médicos sensibilizados con la importancia que este recurso natural tenía entonces para la salud y el tratamiento de determina-

4 Alonso Álvarez, Vilar Rodríguez y Lindoso Tato, 2012, 16.

5 Ibidem, 17-20.

6 Barriola, 1956, 79.

7 Urquía, 1985, 71-72 y 81. 
das enfermedades. No hay que olvidar que todos estos ensayos estaban imbuidos no sólo por el espíritu ilustrado de la época, sino también por ese predominante paradigma higienista que tanto contribuyó a la re-valorización de las aguas en general, tanto minero-medicinales como marinas. $Y$, junto a ello, los propios avances de la química a lo largo de todo el siglo XVIII constituyeron un factor determinante en esa nueva valorización, ya que, al conocer las características de las diferentes aguas, podían ser prescritas para unas enfermedades $u$ otras ${ }^{8}$. En esta tarea no debe olvidarse la labor llevada a cabo por el propio Protomedicato, aunque también por el Real Seminario Patriótico de Vergara, fundado en 1776 por iniciativa de la propia Real Sociedad Bascongada, ya que fue en su seno donde se llevaron a cabo los primeros análisis químicos de las aguas de Cestona. Fue, de hecho, uno de sus profesores más reputados, François Chavaneau, quien los llevó a efecto. Así, en 1782 sacó a la luz los "Análisis de las aguas minerales y en particular de Cestona", realizados en colaboración con Antonio María Munibe y Javier de Eguía, dos miembros muy notables de la Bascongada. Pocos años más tarde realizaría otros dos nuevos análisis, esta vez a instancias del Consejo de Castilla y del Protomedicato 9 . El objetivo de los mismos era la declaración de utilidad pública de las aguas de Guesalaga, algo que se logró el 12 de abril de 1792. Como cabe suponer, esto fue un aspecto importante para la consideración de estas aguas dentro de la oferta termal existente en España, donde poco a poco se estaban ya fundando los primeros balnearios ${ }^{10}$.

Por supuesto, en la realización de estos análisis muchas veces participaron los médicos locales. En el caso de Cestona, por ejemplo, tenemos un estudio realizado por el facultativo de Tolosa Manuel Bernardino Aranguren, quien, en colaboración con lgnacio Antonio Iceta, escribió una memoria fechada el 27 de abril de $1789^{11}$. Esto nos da buena idea del papel tan determinante que jugaron los médicos en estas primeras fases del termalismo en España. Tomando parte en los análisis de las aguas y escribiendo sobre las cualidades de las mismas para según qué enfermedades, estos profesionales se convirtieron en unos auténticos gatekeepers, es decir, en los verdaderos descubridores de los centros termales para las clases altas de la sociedad. De este modo las topografías médicas llegaron a ser un instrumento necesario para seleccionar unas aguas u otras en función de sus características, de acuerdo con las enfermedades que querían ser tratadas. Eran las guías que estas capas acomodadas de la sociedad de la época tenían para estar informadas a la hora de acudir a un balneario u otro. Pero como bien ha señalado Boyer, estos gate-keepers podían ser los descubridores de un lugar, quienes lo diesen a conocer, pero para que dicho espacio tuviese éxito y deviniese un centro turístico, en este caso, un centro termal reconocido, era necesario contar con la presencia de algún miembro destacado de la realeza o de la nobleza. Es decir, de algún star que consagrase dicho lugar ${ }^{12}$. A partir de dicha consagración, y gracias a su

\footnotetext{
8 Bouza, 2000, 3-4.

9 Silván, 1953. Anduaga, 2010, 29-33.

10 Alonso Álvarez, Vilar Rodríguez y Lindoso Tato, 2012, 21-22.

11 El original se encuentra en Archivo General de Guipúzcoa - Gipuzkoako Artxibo Orokorra (en adelante AGG-GAO), JD SM, 38,1.

12 Boyer, 2002, 15.
}

presencia, se iría articulando la oferta de ese espacio de salud y bienestar para la humanidad doliente de la época ${ }^{13}$.

Desde luego, España no fue en esto una excepción y de la misma manera que en Inglaterra los grandes nobles y los distintos miembros de la familia real habían consagrado espacios balnearios tan característicos como Bath o Tunbridge Wells, por ejem$\mathrm{plo}^{14}$, diferentes personalidades de la familia real, ya con la casa Borbón en el trono, impulsaron y consagraron diferentes establecimientos de baños. Así, el balneario de Trillo, en Guadalajara, fue inaugurado en 1778, siendo su promotor Carlos III. Este mismo monarca, por indicación de Pedro López de Lerena, secretario de Hacienda, mandó construir a expensas del Tesoro los baños y la hospedería de Solán de Cabras, en Cuenca. Por su parte, su hijo Carlos IV hizo declarar sus aguas de utilidad pública en 1790, convirtiendo el balneario en Real Sitio ${ }^{15}$. Más lejos de Madrid, también Carlos III encargó en 1785 la reforma de los baños de Archena, en Murcia, afectados por las riadas ${ }^{16}$. La casa de baños del balneario de Sacedón (Guadalajara) fue mandada construir entre 1791 y 1800 por el infante Antonio Pascual de Borbón, también hijo de Carlos III, al percatarse del mal estado en que estaban los baños en los que la reina Mariana de Austria había tomado las aguas, tal como ya se ha dicho ${ }^{17}$. Unos años más tarde Fernando VII fundó en el lugar el Real Sitio de La Isabela ${ }^{18}$.

Evidentemente, no todos los balnearios españoles fueron promocionados por la Casa Real, siendo otros muchos auspiciados por miembros de la aristocracia 0 de las grandes elites locales ${ }^{19}$. Al pertenecer a la sección más alta de la pirámide social, estos actuarían asimismo como stars, consagrando dichos establecimientos de baños. Desde luego, las aguas de Guesalaga de Cestona entrarían en esta categoría, ya que, como se ha dicho, la primera casa de baños fue construida por Vicente de Lili, conde de Alacha. Con un perfil de hombre ilustrado y perteneciente a esos importantes propietarios rurales de la provincia, logró estar muy bien emparentado, al tiempo que a lo largo de su vida llegaría a ocupar el cargo de diputado general de Guipúzcoa en varias ocasiones $^{20}$. Lo que nos da una buena idea de su extracción social. La misma a la que pertenecía el marqués de San Millán, que, como se tendrá ocasión de ver, fue quien finalmente adquirió las aguas de Guesalaga y quien realmente puso en marcha el balneario de Cestona, convirtiéndolo desde principios del siglo XIX en el más importante del País Vasco y uno de los más reputados de España.

\section{Comienzos difíciles para el balneario de Cestona}

Una vez que Vicente de Lili hubo dado noticia de las aguas de Guesalaga y presentado un primer proyecto de construcción

13 Para la construcción de un producto o destino turístico, véase Chadefaud, 1987, 16-20.

14 Hembry, 1990.

15 Sánchez Ferré, 2000, 218-220. Alonso Álvarez, Vilar Rodríguez y Lindoso Tato, 2012, 22.

16 Idem.

17 Mercado Blanco et al., 2003, 75.

18 Aguado Pintor, 2002.

19 Véase, a tal efecto, uno de los casos mejor estudiados, Galicia (Alonso Álvarez, Lindoso Tato y Vilar Rodríguez, 2011).

20 Vidal-Abarca, 1989, 453. 
Cestona en los orígenes del termalismo vasco (1776-1833).

La conformación de un establecimiento de baños en Guipúzcoa

de una casa de baños ante la Real Sociedad Bascongada, el 2 de abril de 1775 daba a conocer su propuesta al Ayuntamiento, iniciándose entonces un litigio entre ambos, al exigirle la autoridad municipal que acreditase documentalmente que era propietario de dichos terrenos. Lili lo demostró y el Ayuntamiento terminó por otorgar su permiso de construcción ${ }^{21}$. Las obras, realizadas por Miguel Antonio de Sarasola, ascendieron a 16.471 reales, de suerte que para el 28 de octubre de 1776 existía ya en Guesalaga un pequeño establecimiento de baños ${ }^{22}$. Se trataba de la primera inversión de capital en el termalismo vasco, bastante modesta, por cierto, aunque se sentaban ya las bases de lo que con el tiempo sería el balneario de Cestona. Aunque los comienzos, como reza el título del epígrafe, no fueron nada fáciles, la verdad. En efecto, la humildad de la casa debió ser tal que, en 1780, Joaquín Aguirre Porcel, marqués de San Millán, elevó una exposición al Consejo de Castilla, pidiendo que se obligase a Lili a introducir mejoras, de manera que, si no las hacía, él mismo estaba dispuesto a hacerse cargo de la explotación de dichas aguas ${ }^{23}$. San Millán sabía perfectamente del gran interés que, como ya se ha dicho, el Consejo de Castilla y el Protomedicato tenían para poner en valor las aguas minero-medicinales del reino, entendiendo que la obra llevada a cabo por Lili no cumplía con estas expectativas. Es más, desde entonces el marqués de San Millán actuó con la intención de hacerse cargo de dicho balneario, consiguiéndolo dos décadas después.

En realidad, la capacidad económica de Vicente de Lili dejaba bastante que desear, ya que desde la década de los ochenta no atravesaba por un buen momento de liquidez. Esto explicaría, por un lado, la falta de inversiones en el balneario, siendo preciso llevar a cabo importantes reformas para poner en valor dicha fuente, y, por otro, el interés demostrado por San Millán para hacerse con su explotación, atendiendo así a los deseos de la Corona, del Protomedicato y del propio Consejo de Castilla. En consecuencia, al no disponer de los recursos económicos suficientes para afrontar tales obras, Lili vio pronto la posibilidad de ceder tales aguas, aunque no tanto al marqués, con quien mantuvo una importante rivalidad en este tema, sino a la villa de Cestona, que también se interesó por los manantiales desde el primer momento. Con una aguda visión de futuro, es muy posible que tanto este municipio como San Millán percibiesen en el negocio termal un nuevo recurso para completar sus economías, por lo que a partir de este momento se inició un intenso juego de intereses a tres bandas en el cual los económicamente más débiles, Lili primero y Cestona después, tenían las de perder, como así fue. El primero porque sus recursos en metálico flaqueaban y aún irían a peor en la década de los noventa, como consecuencia de los perjuicios padecidos durante la Guerra de la Convención. Cestona porque, como la mayor parte de los ayuntamientos guipuzcoanos, también se vio seriamente afectada por la crisis de las haciendas locales durante los años finales del siglo XVIII y principios del XIX24.

21 Archivo Municipal de Cestona, Actas Municipales. En el acta del 2 de abril se hace constar que se ha recibido un Memorial para hacer una casa de baños en el paraje de Ayaquelu y para que se le franqueasen los materiales necesarios.

22 Urquía, 1985, 81.

23 Quesada y Agíus, 1878, 31.

24 Otaegui, 1991.
La contienda contra los convencionales causó graves daños a las propiedades de Vicente de Lili, incluida la casa de baños, lo cual aceleró aún más las necesidades de venta con el objetivo de obtener liquidez. No es que Lili no viera las posibilidades del negocio; simplemente carecía de recursos. Fue entonces cuando optó por enajenar a Francisco Gutiérrez de la Huerta el terreno de las aguas de Guesalaga por la cantidad de $24.000 \mathrm{rv}^{25}$, aunque finalmente la operación no salió adelante, lo cual sólo iba en perjuicio de los baños y de sus clientes. No es de extrañar, pues, que, cuando el ilustrado asturiano Melchor Gaspar de Jovellanos visitó Cestona el 13 de septiembre de 1797, hiciera esta breve, pero significativa, descripción: "en un corralillo una fuente con dos caños, que caen en dos alberquitas hondas, formadas por pizarras, que son los baños, al raso; todo ruin"26. En definitiva, después de transcurridos varios años desde la erección del primer balneario guipuzcoano, apenas se había avanzado en comparación con otras casas de baños del reino, que poco a poco iban ya despuntando. Por ejemplo, en Caldas de Oviedo se construyó en 1773 un primer edificio factura del afamado arquitecto Ventura Rodríguez. Ese mismo año se reabrió la casa de baños de Paterna de la Rivera, en Cádiz. Unos pocos años más tarde, en 1785, reaparecieron los baños de Villavieja de Nules (Castellón) y Horcajo de Lucena (Córdoba). Finalmente, en la década de los noventa inauguraron instalaciones los baños de Marmolejo (Jaén), Puente Viesgo (Cantabria) y Villatolla (Albacete) $)^{27}$. De manera que, aunque la primera iniciativa del termalismo vasco fue temprana, el despegue fue bastante lento.

Frustrada la operación de venta del balneario a Gutiérrez de la Huerta, comenzaron de nuevo las negociaciones a tres, entre Lili, Cestona y San Millán, siendo este último quien tenía mayores posibilidades de hacerse con el establecimiento dada su desahogada posición económica. Esto no fue óbice para que entre Lili y la villa de Cestona se llegara a producir un acuerdo de permuta de propiedades. El negocio para Lili era francamente atractivo, pues de este modo se libraría de tener que hacer las obras exigidas por el Consejo de Castilla. Cestona lograría hacerse con Guesalaga, pero ahora el problema lo tenía la villa: ¿con qué recursos pensaba abordar la reforma del balneario? En el contexto de la mencionada crisis de las haciendas locales, carecía de medios suficientes para llevar a cabo una obra de tal envergadura. Es lo que seguramente pensó Joaquín Aguirre Porcel. No sorprende, por tanto, que, a partir de ese instante, la estrategia de San Millán consistiera en presionar tanto a la villa de Cestona, con la que no había podido llegar a un acuerdo previo, como al Consejo de Castilla, presentándose él como la mejor solución para poner en valor las aguas de Guesalaga. Disponiendo de numerario suficiente para acometer las obras, era preciso mover todos los hilos para forzar finalmente a Vicente de Lili a que le vendiese las aguas y el balneario. Y a no dudar que lo hizo. De hecho, la única oportunidad que tenía Cestona de continuar con la operación era vender parte de sus bienes y crear nuevos arbitrios para aumentar

\footnotetext{
25 Archivo Histórico de Protocolos de Guipúzcoa (en adelante AHPG), 2/1842, Errazti, 8 de septiembre de 1796.

26 Jovellanos, 1915, 374.

27 Sánchez Ferré, 2000, 218-220. Alonso Álvarez, Vilar Rodríguez y Lindoso Tato, 2012, 22.
} 
la recaudación. Opción que fue rechazada por el fiscal enterado de este expediente ${ }^{28}$.

En tales circunstancias, el fiscal también decidió que los planos para la ejecución de las obras del balneario de Cestona fuesen examinados por la Real Academia de San Fernando, siendo sometidos a su juicio sendos proyectos, el de Cestona-Lili y el de San Millán. Al mismo tiempo, se solicitaba al corregidor de la provincia de Guipúzcoa que evacuase un informe sobre la situación. Ambos pasos fueron determinantes para inclinar la balanza a favor del marqués. De hecho, el corregidor Alfonso Durán tuvo preparado su informe al mes siguiente, decantándose a favor de la opción de Aguirre Porcel ${ }^{29}$. En cuanto a la Academia, también se posicionó a favor del proyecto firmado por el académico Alejo de Miranda frente al de Ignacio Vicente de Errazti, en representación de Cestona ${ }^{30}$. Por supuesto, eran buenas noticias para San Millán, plasmadas en una providencia del Consejo a favor de la propuesta del marqués y del plano de Miranda, aunque con una matización importante, que, desde luego, no le iba a gustar en absoluto: que si en el plazo de cuatro años la villa de Cestona pudiese reintegrar al marqués los gastos derivados de la obra, tendría derecho a hacerlo y a quedarse, por tanto, con Guesalaga; si no, dichas aguas seguirían en manos de San Millán ${ }^{31}$.

Ante semejante providencia, San Millán tuvo que recurrir a todas sus influencias, que no debieron ser pocas. En los términos en los que estaba redactado dicho escrito, no había garantías jurídicas para la inversión en Guesalaba, por lo que el marqués no estaba dispuesto a arriesgar en una operación poco segura. Al final, el Consejo accedió a su petición, resolviendo que pagase a Vicente de Lili el precio que conviniesen 0 , en caso contrario, los 29.000 reales que aquel venía pidiendo en los últimos años. Finalmente, el precio estipulado por ambas partes se quedó en los 26.500 reales $^{32}$.

Resuelto este problema, San Millán pretendía que el proyecto de la obra lo ejecutase un maestro de obras y no un académico como Alejo de Miranda. La razón era muy simple: a este habría que pagarle bastante más que a un maestro de obras. Evidentemente, la Academia de San Fernando se opuso a semejante pretensión ${ }^{33}$, pero el marqués volvió a jugar la carta de la influencia y de la velada amenaza de continuar adelante con el proyecto. Así lo entendió el propio Consejo, que terminó por atender la petición de San Millán desoyendo el dictamen de la Real Academia de San Fernando, ya que se corría el riesgo de que abandonase la

28 Archivo Histórico Nacional (en adelante AHN), Fondos de Consejos Suprimidos, $1532,15,1{ }^{\text {a }}$ pieza, informe del fiscal de 19 de noviembre de 1800 , fols. 159-160.

29 AHN, Fondos de Consejos Suprimidos, 1532, 15, 1. ${ }^{\text {a }}$ pieza, informe del corregidor de Guipúzcoa del 27 de julio de 1801, fols. 217-222.

30 Archivo de la Real Academia de Bellas Artes de San Fernando (en adelante ARABASF), expediente 2-30-6, escrito del 28 de agosto de 1801 de Silvestre Pérez, de la Comisión de Arquitectura, y Juntas de la Comisión de Arquitectura, t. I, 30 de octubre de 1800. El 27 de agosto de 1801 se delibera entre los proyectos de Miranda y Errazti, prefiriendo el primero.

31 AHN, Fondos de Consejos Suprimidos, 1532, 15, 1. ${ }^{\mathrm{a}}$ pieza, providencia del Consejo del 27 de octubre de 1801, fol. 230v.

32 http://dokuklik.snae.org/badator_zoom.php?cdc=035\&cdd=00323. Copia del Archivo Lili.

33 ARABASF, Juntas de la Comisión de Arquitectura, t. I, 28 de abril de 1803, fol. 359 . empresa. Una real orden del 16 de enero de 1804 autorizaba al marqués a hacer la casa de baños de Guesalaga sin sujetarse al dictamen de la Academia, lo cual suponía una victoria en toda regla y probaba muy a las claras su poder de influencia. Todo parece apuntar a que hubo intervención del mismísimo Godoy para que sus planes saliesen adelante ${ }^{34}$. Como cabe suponer, desde entonces se abría una nueva etapa para el balneario de Cestona, con un edificio, ahora sí, digno de tal nombre.

\section{El balneario de Cestona, el primero del País Vasco}

Una vez en manos del marqués de San Millán las cosas empezaron a cambiar sustancialmente en el devenir de este balneario. Así, fue bajo su propiedad cuando Cestona se convirtió en la primera gran casa de baños del País Vasco. Si hasta ese momento había sido un establecimiento pequeño y en malas condiciones, pensado, sobre todo, para satisfacer una demanda corta y mayoritariamente local, con Aguirre Porcel como dueño, su situación cambió considerablemente. De hecho, mediante una real orden de 16 de enero de 1804 se le concedía la facultad de ejecutar los trabajos correspondientes, de forma que el nuevo edificio estuvo ya listo para la temporada de baños de 1807. El coste de las obras de Guesalaga habría importado 60.000 pesos "más o menos", según declaraba el propio marqués en su testamento del 24 de julio de $1816^{35}$. Lo que suponía unos novecientos mil reales. Se trata de una cifra respetable y, desde luego, muy lejana de aquella modesta inversión que en su día hiciera Vicente de Lili. Parecería que quedaban atrás esos turbulentos años de sus difíciles comienzos cuando, en verdad, la situación se complicó sobremanera con el estallido de la Guerra de la Independencia, la cual tuvo especial incidencia en el País Vasco. Primero, por ser territorio fronterizo con Francia y, por lo tanto, lugar de paso, y a veces de acantonamiento, del Ejército napoleónico. Y segundo, porque las tres provincias vascas quedaron sometidas a la administración de los franceses durante el devenir de la guerra.

Al parecer, San Millán no llevó a cabo la explotación directa del establecimiento. Ignoro quién estuvo al frente del mismo en la temporada de 1807, pero sí sabemos que en la primavera del año siguiente entraron como inquilinos Antonio Chardon y su mujer $M .{ }^{\text {a }}$ Cruz Larrañaga, quienes permanecieron en la casa hasta diciembre de ese mismo año de 1808. La fuente señala que, debido a las desavenencias por el pago de la renta entre el marqués y Chardon, este terminó por abandonar la casa ${ }^{36}$. La grave situación por la que atravesaba el país no debió desalentar, sin embargo, al marqués en su deseo de seguir explotando los baños de Cestona, pues el 14 de febrero de 1809 firmaba una escritura de arriendo de dichos baños con Ramón Lizaso, que fue capitán de infantería, y su mujer M. ${ }^{a}$ Catalina Zubizarreta, quienes se comprometían a hacerse cargo del establecimiento desde la primavera próxima y por un periodo de seis años, abonando 1 real diario y $1 / 2$ real por criados, criadas y mozos de mulas y por los verdaderos pobres.

\footnotetext{
34 Rodríguez-Sánchez, 1992, 112-113.

35 AHN, Fondos de Consejos Suprimidos, 1532,15, II. ${ }^{a}$ parte, pieza 2. ${ }^{a}$ corriente, fol. $319 \mathrm{v}$.

36 Archivo Municipal de San Sebastián: Archivo del Marqués de San Millán (en adelante AMSS: AMSM), 48, 88.
} 
Cestona en los orígenes del termalismo vasco (1776-1833).

La conformación de un establecimiento de baños en Guipúzcoa

Las ganancias de la mesa de billar irían a medias entre ambas partes $^{37}$. En principio, de acuerdo con las cláusulas del contrato, este arrendamiento debería haberse extendido hasta la primavera de 1814, es decir, prácticamente a lo largo de toda la conflagración, por lo que cabe pensar que este debió sentirse claramente alterado. A decir verdad, no sé qué pasó en esos años en el balneario de Cestona, si bien, gracias a una declaración posterior de Juan Bautista Lizaso, apoderado del marqués en dichos baños, sabemos que Ramón Lizaso y Catalina Zubizarreta estuvieron al frente del balneario entre 1812 y 1825 bajo fórmulas distintas, aunque debieron estar desde antes: cuando menos, desde 1809, como se ha dicho.

Por los indicios que tenemos, parece que las cosas permanecieron tal cual hasta que en 1821, a instancias de la villa de Cestona, se expidió una real orden mandando que los propietarios del balneario hiciesen nuevas obras en el lugar destinado a bañeras. Atendiendo a ella, fue en 1822 cuando se llevó a cabo la construcción de la nueva casa de baños según plano y bajo la dirección del arquitecto Ugartemendía ${ }^{38}$, elevándose el coste a unos ciento treinta mil reales, a los que hubo que añadir otros 30.000 por nuevas obras de necesidad y comodidad realizadas en 1826 y 1827 . Lo que hacía una suma aproximada de no menos de 1.060 .000 reales de inversión hasta la fecha, cantidad muy a tener en cuenta ${ }^{39}$. Estas mejoras, sin embargo, contrastaban con la dejadez de los inquilinos en la marcha del balneario. Según expresión de Esteban Peyron, "en todos los ramos de ella, y especialmente en el aseo, en los alimentos, en el método y orden de tomar las aguas y baños, todo era arbitrariedad, y cada enfermo Médico de sí mismo" ${ }^{40}$. Ante las constantes quejas de los clientes, quien había sido nombrado director del balneario por la marquesa de San Millán, Vicente Aberasturi, canónigo de la Colegial de Vitoria, decidió intervenir, en especial en lo referente a la fijación de precios y a las condiciones del servicio, para tratar de resolver la situación y atajar los desmanes que se estaban cometiendo en dicho establecimiento.

Estas acusaciones de Peyron contra Lizaso y su esposa no han podido ser contrastadas, por lo que hay que tomarlas con cautela. Primero, porque el número de visitantes que tuvo el balneario en 1824 y 1825, 416 y 522, respectivamente, estuvo muy por encima de los concurrentes durante los conflictivos años del Trienio Liberal ${ }^{41}$. Segundo, porque después de tantas temporadas al frente del negocio, acusaciones de esta naturaleza

37 AMSS: AMSM, 48, 88: Escritura de Arriendo de los Baños de Guesalaga, 14 de febrero de 1809.

38 Según Zeaorrote, 1822, 120-121, "el ilustrado Conde de Villa-fuerte (...), apoyando las justas solicitudes del pueblo de Cestona, mediando con el gobierno, y allanando otras muchas dificultades, ha conseguido el que todos, cada cual por su parte, contribuyan a mejorar el establecimiento, y aun el que el mismo propietario se haya prestado a costear las reformas y adiciones, reclamadas por la necesidad, y la experiencia. Cediendo a sus insinuaciones imperiosas el celebrado arquitecto Ugartemendia ha estendido los planes, y encargándose de hacerlos ejecutar, se ha dado principio a las obras bajo de su misma dirección".

39 AMSS: AMSM, 48, 91, fol. 14v.

40 AHN, Fondos de Consejos Suprimidos, 1532, 15, II. ${ }^{a}$ parte, pieza 2. ${ }^{a}$ corriente, solicitud de Esteban Peyron, en nombre de la marquesa de San Millán, del 10 de enero de 1829 , fol. $397 \mathrm{v}$.

41 AHN, Fondos de Consejos Suprimidos, 1532, 15, 3. a pieza, declaración de Juan Bautista Lizaso del 19 de julio de 1827, fol. 22r. no dejan de ser llamativas. Y tercero, porque Peyron era parte interesada, ya que, en nombre de la marquesa de San Millán (Rafaela Valdivia), estaba solicitando al Consejo de Castilla la aprobación del reglamento de baños elaborado por Aberasturi, con el cual no estaban de acuerdo los inquilinos. En realidad, Aberasturi se vio en la obligación de redactar dicho reglamento con la esperanza de que Catalina Zubizarreta lo cumpliese y siguiese con el inquilinato de la casa de baños. Pero no fue así y esta decidió abandonar el balneario, no estando dispuesta a someterse a dichas normas. De manera que para 1826 Lizaso y Zubizarreta ya no tenían en arrendamiento Guesalaga. Lo cual abrió un nuevo periodo en el devenir de este establecimiento. De hecho, en 1826 Aberasturi, en nombre de Rafaela Valdivia y, por ende, del propio marqués de San Millán (su hijo), firmó una escritura de arrendamiento de la casa y baños de Cestona con Juan Duhart (o Duart), vecino de Irún ${ }^{42}$. La concesión se haría por 9 años a contar desde el 1 de noviembre de 1825 y por una renta anual de 24.000 reales, a pagar desde el 1 de noviembre del mismo año de la escritura.

\section{LA NOVEDAD DE LA COMPETENCIA}

EN LOS COMIENZOS DE UNA ECONOMÍA LIBERAL

El hecho de que Lizaso y Zubizarreta se viesen obligados a abandonar el balneario de Cestona no quiere decir que no continuasen en el negocio de la hotelería, tal como vamos a tener ocasión de ver. De hecho, lejos de amedrentarse, crearon una casa de huéspedes en las proximidades del establecimiento de baños, lo cual suponía hacer claramente la competencia al balneario de los marqueses. Hasta tal punto que Catalina Zubizarreta, ya viuda de Lizaso ${ }^{43}$, en 1827 otorgó un poder especial a Felipe Antonio Piñeiro, agente del Supremo Consejo de Castilla, con el fin de evitar que el entonces inquilino de Guesalaga, Juan Duhart, cobrase precios más elevados a quienes se alojasen en el pueblo 0 en su nueva fonda respecto de los que pagaban los hospedados en las instalaciones de San Millán. En concreto, había la intención de cobrar el doble, lo que constituía, a todas luces, un abuso ${ }^{44}$. En realidad, Duhart se limitó a cumplir con el reglamento de baños de Guesalaga redactado por Aberasturi, el cual, como ya se ha dicho, había sido fuente de conflicto con Lizaso y Zubizarreta. Pues bien, ahora, con la creación de una hospedería tan cerca del balneario, el conflicto con los marqueses de San Millán estaba servido. La justificación de este incremento en el precio no podía ser más clara:

"son los precios de las asistencias los más bajos del Pais, y no puede permitir que sean atacados los productos de una finca en la que tiene hechos el dueño tantos gastos y está haciendo aún para la comodidad, y en la que los enfermos pobres han recivido y recibirán

42 AHPG, 3/0096, Legarda, 21 de enero de 1826.

43 Ramón Lizaso falleció en diciembre de 1826 (Archivo Histórico Diocesano de San Sebastián, DEAH/F06.159//3282/004-01, f.39r,n. ${ }^{\circ}$ 21/D1826-12-22).

44 AHN, Fondos de Consejos Suprimidos, 1532, 15, II. ${ }^{\text {a }}$ parte, pieza 2. ${ }^{\text {a }}$ corriente, fols. 286 y $289 \mathrm{v}$. Según la cláusula 7 del contrato de arrendamiento, los precios serían los siguientes: 4 reales por baño, 1 por sábana y 8 por su toma en bebida (AHPG, 3/0096, Legarda, 21 de enero de 1826, fol. 17). 
graciosamente una medicina para lo q. nada contribuye la Dueña de la nueva casa" ${ }^{\prime 4}$.

Pese a las críticas antes mencionadas de Peyron, Catalina Zubizarreta no se arredró e hizo una reclamación contra dicho reglamento, provocando la apertura de un expediente. Experiencia, capacidad de emprendimiento y capital debieron ser los tres elementos que precisaron Lizaso y su esposa para abrir su hospedería. Incluso no estaría de más hablar de un cierto atrevimiento, ya que, en vez de abrir su casa en el mismo pueblo de Cestona, lo hicieron en las cercanías del establecimiento de baños en que habían trabajado. El negocio estaba allí, junto a las aguas, y ellos lo sabían. Tantos años de inquilinato les debió hacer aprender muchas cosas. No es extraño, por consiguiente, que Rafaela Valdivia, en representación de los intereses del marquesado de San Millán, tratase de boicotear la iniciativa de Catalina Zubizarreta. Aunque la verdad era que Valdivia no tenía un derecho exclusivo sobre todo lo que implicaba el negocio balneario. En otras palabras, Catalina Zubizarreta estaba apelando al derecho de competencia. Los San Millán habían construido su casa de baños en el terreno que habían adquirido de Lili, pero eso no les daba la exclusividad de alojamiento en todo el municipio de Cestona. Todavía más, el hecho de pretender cobrar el doble a los huéspedes de la casa de Zubizarreta era difícil de mantener, habida cuenta de que las tasas de baños y aguas emanaban del Supremo Consejo y eran comunicadas al corregidor de la provincia. De ahí que Catalina Zubizarreta suplicase al Consejo una orden para que el corregidor evitase que Duhart alterase los precios cuando la temporada estaba próxima a empezar.

De este modo, el corregidor de Guipúzcoa, Rafael de Aynat y Sala, emitió un informe el 3 de junio de $1827^{46}$. En él se hacía constar la diferencia de precios, que era evidente. La casa nueva de Zubizarreta no sólo podía hacer la competencia a Guesalaga, sino que también podía suponer que grupos sociales menos pudientes pudiesen acceder a la toma de baños, en cuyo caso estaríamos ante el típico ejemplo de capilarización del que en su día habló Marc Boyer (2002). Es decir, que las clases más bajas imitaban a las más altas en sus prácticas sociales; en concreto, en la toma de las aguas. Aynat calculaba en unos trescientos los concurrentes al establecimiento de baños de San Millán, lo que podía suponer unos ingresos anuales al arrendador del orden de la nada despreciable suma de 24.000 reales, cuando la cantidad invertida en las obras del establecimiento era de 500.000 rea$\operatorname{les}^{47}$. En consecuencia, concluía que Zubizarreta tenía la entera

45 AHN, Fondos de Consejos Suprimidos, 1532, 15, II. ${ }^{a}$ parte, pieza 2. ${ }^{a}$ corriente, Reglamento de baños de Guesalaga, por Vicente Aberasturi, 20 de mayo de 1827 , fol. $393 \mathrm{v}$.

46 AHN, Fondos de Consejos Suprimidos, 1532, 15, II. ${ }^{a}$ parte, pieza 2. ${ }^{a}$ corriente, fols. 304-306.

47 Como ya se ha dicho, esta cantidad contrasta sensiblemente con la declarada por el marqués de San Millán en su testamento, donde se hablaba de unos novecientos mil reales, suma que, posiblemente, fuese cierta, dado el carácter privado de dicho documento. La cifra dada por el corregidor debe referirse únicamente a las obras exteriores ejecutadas, pero no a las obras subterráneas, tan costosas, pero a la vez imprescindibles en un establecimiento de baños donde se debe preservar en todo momento la calidad, pureza y temperatura de las aguas. Esa cuantía de 500.000 fue confirmada por el procurador Felipe Santiago Gallo en su recurso de 17 de mayo de 1828 (AHN, Fondos de Consejos Suprimidos, 1532, 15, II. ${ }^{a}$ parte, pieza 2. ${ }^{a}$ corriente, fol. $323 \mathrm{v}$ ). Hay que mencionar que el coste en las libertad de alojar huéspedes en su casa, fijando los precios que conviniese, negando la exclusividad del marquesado de San Millán en este terreno. Evidentemente, el corregidor estaba haciendo una apuesta decidida por la libre competencia, en un momento en que todavía las resistencias a los principios liberales no estaban superadas. Estaba claro. Catalina Zubizarreta era vista como una competidora que conocía bien a los San Millán y el negocio termal, algo visto con muy malos ojos por Rafaela Valdivia.

El informe de Aynat provocó que la Sala de Gobierno del Consejo de Castilla dictase una providencia instándole a establecer con urgencia un arancel para los baños de Cestona. Para ello, el corregidor habría de tener en cuenta las tarifas vigentes en Sacedón y en los demás del reino, así como oír al marqués de San Millán y evitar la menor alteración de precios y horas del uso de dichas aguas, manteniéndose como estaban, siendo igual para los que se alojasen en el balneario como para los hospedados en la casa de Zubizarreta ${ }^{48}$. Comenzada ya la temporada de baños, el corregidor, en tanto se formaba y aprobaba el arancel definitivo, ordenó que se fijasen unas directrices para el régimen y gobierno de los baños de Guesalaga. En ellas se mantenían los precios de cuatro reales por baño, más uno por sábana, y ocho reales por el agua bebida, no estableciendo distinción alguna entre los alojados en el establecimiento de baños 0 en cualquier otra casa ${ }^{49}$.

Así las cosas, el arancel no estuvo finalizado hasta el 12 de abril de $1828^{50}$ y en él se ratificaba que las tarifas serían iguales para todos, es decir, bien para los alojados en el establecimiento de los San Millán, bien en la casa de Zubizarreta u otras. Como no podía ser de otra manera, Rafaela Valdivia no compartía en absoluto el posicionamiento del corregidor de Guipúzcoa, prolongándose esta situación durante unos años. Fue el procurador Felipe Santiago Gallo el encargado de presentar un recurso ${ }^{51}$. En él se desmentía la cifra dada por Aynat y se insistía en el más de un millón de reales invertidos en el establecimiento, de suerte que estaríamos hablando de una cantidad francamente importante, por lo que se consideraban "ciertamente acreedores a recompensas, o por lo menos a una proteccion que ponga su propiedad a cubierto de la ruina que ha proyectado una mujer envidiosa del bien ageno, y atenta solo a su interés" (fol. 323v). La apelación a la protección no puede ser más clara.

Todo lo cual nos da buena idea de su consideración del negocio. Parece responder a una mentalidad del pasado, habida cuenta de que la posesión de un molino, una ferrería, un caserío o un sembradío había proporcionado unas rentas más bien estables a sus propietarios durante décadas. Los San Millán pertenecían a esa nobleza propietaria dueña de numerosos bienes de este tipo. Pero

obras subterráneas en Cestona fue bastante elevado en los primeros años debido a los problemas de caudal. Este ha sido un aspecto pródigamente señalado por Rodríguez-Sánchez, 1992, 114-115.

48 AHN, Fondos de Consejos Suprimidos, 1532, 15, II. ${ }^{a}$ parte, pieza 2. ${ }^{a}$ corriente, providencia del 26 de junio de 1827 , fol. $309 \mathrm{v}$.

49 AHN, Fondos de Consejos Suprimidos, 1532, 15, III pieza, orden del corregidor de Guipúzcoa del 19 de julio de 1827, fols. 25-26r.

50 AHN, Fondos de Consejos Suprimidos, 1532, 15, III pieza, arancel del corregidor de Guipúzcoa para los baños de Cestona del 12 de abril de 1828, fols. 64-65.

51 AHN, Fondos de Consejos Suprimidos, 1532, 15, II. ${ }^{\mathrm{a}}$ parte, pieza 2. ${ }^{\mathrm{a}}$ corriente, recurso de Felipe Santiago Gallo del 17 de mayo de 1828, fols. 321-327. 
Cestona en los orígenes del termalismo vasco (1776-1833).

La conformación de un establecimiento de baños en Guipúzcoa

un balneario entendido como una empresa era algo bien distinto. Primero había que hacer una inversión fuerte (como la hecha por Joaquín Aguirre Porcel) y después había que atraer a la clientela. Pero había otros balnearios en España que podían competir con el de Cestona. Sin embargo, la ausencia de otras casas de baños en el País Vasco durante esos años había hecho que Guesalaga fuese el único establecimiento de baños de la zona. Pero ahora que aparecía una nueva competidora se recurría a la protección, cosa que iba en contra de la libertad económica propugnada por el liberalismo. Si se abogaba por la libertad de los factores de producción, incluido el capital, la postura mantenida por Rafaela Valdivia era contraria a esta proclamación. El capital podía circular libremente y ser invertido donde su poseedor considerase que le podía rendir más y así hacer progresar la economía. Apelando a este planteamiento, ¿era posible negar a Catalina Zubizarreta el derecho a invertir su capital en una hospedería? Una hospedería que podría ser ubicada donde ella considerase más oportuno, siempre y cuando se respetase la propiedad de San Millán, cosa que Zubizarreta estaba haciendo.

Dicho esto, el recurso que argumentaba Rafaela Valdivia para profundizar en la protección de su negocio radicaba en los escasos beneficios que proporcionaba el establecimiento al marquesado de San Millán, insistiendo, por tanto, en la moderación de los precios cobrados a los usuarios de la casa de baños, a pesar de las mejoras introducidas en ella en 1822, por ejemplo. Según indicaba el procurador, los precios, además de moderados, se habían contenido, por lo que el margen de ganancia había sido más bien escaso. La razón estribaba en que el objetivo principal de San Millán siempre había sido el beneficio de la humanidad y la salud pública. Calculando en un millón de reales la suma desembolsada hasta 1825, a un interés del $4 \%$, nada abusivo, por otra parte, el producto anual debía haber ascendido a unos 40.000 reales, cantidad muy lejana a la realidad. Pero incluso rebajando dicho porcentaje a la mitad, estaríamos hablando de 20.000 reales, cifra que, de promedio, tampoco se alcanzaba, tal como puede apreciarse en la siguiente tabla.

Tabla 1. Productos rendidos al marqués de San Millán por la casa, aguas y baños de Cestona desde 1817 hasta 1825

\begin{tabular}{|l|l|l|l|}
\hline & Aguas y baños & Casa & Total \\
\hline 1817 & $13.824,24 \mathrm{~ms}$ & 6.500 & $20.324,24$ \\
1818 & 11.256 & 6.500 & 17.756 \\
1819 & 11.980 & 6.500 & 18.480 \\
1820 & 10.093 & 6.500 & 16.593 \\
1821 & $11.342,27$ & 6.500 & $17.842,17$ \\
1822 & $8.075,19$ & 6.000 & $14.075,17$ \\
1823 & 9.027 & 4.808 & 17.835 \\
1824 & 15.309 & 8.000 & 23.309 \\
1825 & $19.688,22$ & $10.038,16$ & $29.716,16$ \\
\hline & & & $175.932,8$ \\
\hline
\end{tabular}

Media anual: 19.548 r, $2 \mathrm{~m}$ y $4 / 9$ de otro.

Fuente: AHN, Fondos de Consejos Suprimidos, leg.1532, exp.15, II. ${ }^{a}$ parte, pieza 2. ${ }^{a}$ corriente, Felipe Santiago Gallo, procurador (en nombre de Rafaela Valdivia), fol. 318 r.

El hecho de que la casa de Guesalaga rindiese al marquesado por valor de menos de un $2 \%$ anual de lo invertido parece una prueba evidente de que el termalismo, al menos el vasco, no era un negocio excesivamente lucrativo. Estos magros beneficios y la propia contención de los precios hacían pensar a Rafaela Valdivia que la casa de Catalina Zubizarreta podría suponer la ruina de los intereses de San Millán, ya que no se veía ninguna necesidad de erigir una nueva hospedería, teniendo en cuenta que la del marqués tenía una capacidad de hasta cien personas, por lo que, en realidad, la actividad termal vasca de la época se estaba moviendo en cifras más bien modestas. Asimismo, en el recurso se eximía de culpabilidad a Duhart de la subida de precios a los no alojados en Guesalaga, ya que el responsable de tal medida había sido el representante del marqués y siempre contemplándose dos restricciones, a saber: mayor tarifa para quienes se alojasen en la casa de Zubizarreta siempre que hubiese sitio en la suya y no alterándose el precio para las personas sin capacidad de costearlo. Queda claro que para Rafaela Valdivia, la casa de la ex inquilina suponía una amenaza para el negocio hotelero ligado al propio balneario, más aún cuando se trataba de hacer del balneario de Cestona "el mejor de todos los de su clase en España, y aun de algunos de los Extrangeros" (fol. 326v).

Con todo, la petición de la marquesa de San Millán no tuvo efecto y el arancel formado por el corregidor inicialmente se cumplió, a pesar de que no había escuchado a los marqueses a la hora de formarlo, tal como establecía la providencia del 26 de junio de 1826. En realidad, no fue una negligencia o falta del corregidor, sino que, según consta en una carta del marqués de Altamira, corregidor de la provincia de Granada, al propio Aynat, el marqués de San Millán no se encontraba en su casa de la capital andaluza, debiendo estar con su madre en el balneario de Lanjarón y teniendo previsto desplazarse posteriormente a Gibraltar ${ }^{52}$. Por tanto, al no poder escuchar a los interesados, el corregidor decidió dictar el arancel por su cuenta y riesgo. Razón por la cual la marquesa viuda de San Millán solicitó su devolución al haberse incumplido una de las premisas de la providencia mencionada.

\section{LA CUESTIÓN FORAL}

Una novedad importante dentro del argumentario de Rafaela Valdavia para oponerse al reglamento emitido por Aynat fue el recurrir al expediente foral, tratando de implicar en el caso a la Diputación Foral de Guipúzcoa ${ }^{53}$. En concreto, fue Narciso Clavería, administrador de la casa de baños de Cestona en el momento de entrar en vigor el arancel, quien se encargó de dirigirse a ese organismo quejándose de que dicho arancel no había sido aprobado aún por el Consejo y poniéndole sobre aviso de ser una actuación contraria a los fueros. Para Clavería, según carta del 25 de mayo de 1828, el documento elaborado por el corregidor era una mezcla de reglamento de buen gobierno, arancel y policía, yendo mucho más allá de lo que el Consejo le había solicitado, menoscabando así los derechos de propiedad y las propias libertades de la provincia de Guipúzcoa. El mandato del Consejo se refería exclusivamente a los usos de las aguas y baños de Cestona y no a otras

52 AHN, Fondos de Consejos Suprimidos, 1532, 15, III pieza, fol. 54, carta del corregidor de Granada al corregidor de Guipúzcoa, 13 de octubre de 1827.

53 Salvo que se indique lo contrario, la documentación citada a continuación se halla en AGG-GAO, JD IM 1/19/111. 
cuestiones como los precios de la posada, por ejemplo. Según Clavería, el corregidor se había extralimitado en sus funciones. Más aún porque había obligado a su cumplimiento al arrendatario de los baños cuando aún no había sido aprobado por el Consejo ni había logrado el pase de la Provincia tras su examen. Hay que recordar que el pase foral consistía en el examen de cartas, órdenes y provisiones reales llevado a cabo por la Diputación para salvaguardar los privilegios, franquezas y libertades contenidos en los fueros. En tales circunstancias, el administrador del balneario se preguntaba si el arrendatario debía o no hacer cumplir dicho arancel, rogando a la Diputación que no tuviese que aplicarse hasta conseguir el pase de la Provincia.

Los argumentos esgrimidos por Clavería eran contundentes, la verdad. Aynat había precipitado la imposición de su arancel sin haber obtenido previamente la aprobación del Consejo. Pese a todo, el encargado de asesorar a la Diputación ante semejante petición fue Luis Arocena, quien, en su informe de 29 de mayo de ese mismo año, aconsejaba que la institución foral no entrase en la cuestión. Según él, el corregidor actuaba como ejecutor de las providencias del Consejo, por lo que los considerados agraviados por sus decisiones se deberían dirigir al propio Consejo, no correspondiendo, pues, a la Diputación tomar conocimiento sobre la legalidad o ilegalidad de los procedimientos del corregidor. Como era de esperar, Clavería no quedó satisfecho ni con este informe ni con la respuesta de la Diputación a su petición, por lo que volvió a dirigirse a esta institución con un nuevo escrito del 28 de junio. Insistiendo una vez más en los excesos cometidos por el corregidor en sus atribuciones, rechazaba que los vicios del procedimiento afectasen sólo al Consejo, ya que aquellos iban en contra de los propios fueros. No sólo no había obtenido el preceptivo pase de la Provincia, invadía competencias en el ramo de policía e iba contra los derechos de propiedad de los guipuzcoanos. En consecuencia, en tono conciliador, aceptaba la prohibición de alterar el precio y el orden de los baños, tal como marcaba el arancel, pero no así la imposición de los gravámenes y restricciones en él contenidos. Aquí cabe hablar de una contradicción en su exposición, ya que o se rechazaba completamente el arancel o se admitía en su totalidad, por el mero hecho de que debía ser aprobado por el Consejo y obtener después el pase de la Provincia. Por eso, la intencionalidad de Clavería era clara: tratar de revisar la posición expuesta por Luis Arocena. Y lo consiguió, ya que sus reclamaciones no cayeron en saco roto, pues el ente foral solicitó esta vez dos dictámenes, firmados por Ramón Lizarzaburu y José de Churruca, respectivamente.

En el informe de Lizarzaburu (Tolosa, 8 de julio de 1828) se insistía, en primer lugar, en que la autoridad del corregidor debía ser meramente judicial, rechazando que pudiera invadir facultades referidas al buen régimen, comodidad y policía, reservadas al ente foral. Dicho esto, Lizarzaburu se posicionaba en contra de arancel o reglamento alguno que fuese restrictivo con los derechos de propiedad y, en consecuencia, de obstruir el libre comercio. No obstante, argumentaba que al corregidor se le había encargado la formación de un arancel, sin que este pudiese ser impuesto sin previa autorización del Consejo y habiendo oído al marqués. Ambas cosas no se habían producido, además de ha- berse extralimitado en las reglas de policía, que no le competían, y en la fijación de precios para efectos y servicios, instando a que el inquilino llevase un libro rubricado, lo cual iba en contra del derecho de propiedad y de la libertad personal. Con todas estas restricciones, se preguntaba Lizarzaburu, ¿quién iba a estar dispuesto a arrendar este establecimiento 0 a invertir en edificios de esta naturaleza? No obstante, sí se posicionaba a favor de la competencia, indicando que sólo de esta forma se moderarían los precios. La fórmula, pues, de fijar un arancel no le satisfacía, pensando más en la libre concurrencia, de suerte que cualquier habitante de Cestona pudiese establecer una posada. La competencia era más eficaz que el método restrictivo propuesto por Aynat. Además, ¿por qué el arancel habría de aplicarse sólo al arrendatario de la casa de Guesalaga y no a Catalina Zubizarreta? Si se optaba por la verdadera libertad del capital, la competencia terminaría por fijar el precio de mercado y no tanto un arancel que, por otra parte, invadía competencias de la Diputación Foral.

También era contrario al fuero la manera en que el corregidor pretendía imponer su arancel al arrendatario. Si hasta la fecha se habían presentado a consideración de la Diputación para la obtención del pase de la Provincia tanto los reales decretos como las provisiones de los tribunales superiores, cuanto más un reglamento formado por un juez inferior (el corregidor) que actuaba por comisión de la superioridad (el Consejo). Según Lizarzaburu, el corregidor no tenía facultad alguna para establecer aranceles reglamentarios en ningún establecimiento de la provincia. El Consejo sólo le había encargado hacer un mero proyecto de arancel, que debería ser aprobado o reformado por ese organismo. No estaba capacitado para exigir la observancia de dicho arancel, siendo antiforal su pretensión, por lo que correspondía a la Diputación oponerse a su plantificación. Hasta que no pasase por el Consejo, el ente foral no estaría en condiciones de dar el pase de la Provincia para su aplicación, debiéndose considerar ofendida en sus atribuciones ante las pretensiones del corregidor.

El segundo informe, como se ha dicho, fue elaborado por José de Churruca (Motrico, 8 de julio de 1828) e insistió en argumentos muy parecidos. En su escrito denunciaba el doble exceso del corregidor, en el fondo de la materia y en el modo o trámite de ella. En el fondo, porque el cometido encomendado se ceñía al uso de las aguas de los baños de Cestona, habiéndose propasado al establecer restricciones sobre otros servicios. En el modo, por haber omitido la audiencia del marqués de San Millán y por no haber obtenido la sanción del Consejo, aspecto considerado fundamental, pues si no, "será un plan o informe desnudo de toda investidura legal que le imprima fuerza de ley u obligatoria". Ante semejante carencia, Churruca recomendaba a la Diputación ejercer su autoridad tutelar sobre el establecimiento de baños. El corregidor no podía pretender implantar un arancel con semejantes excesos en el modo, pero, además, porque, caso de ser sancionado por el Consejo, para entrar en vigor en Cestona, se precisaba del pase de la Provincia. Aynat había vulnerado la autoridad foral de Guipúzcoa al haber publicado y mandado cumplir su arancel sin pase previo, razón por la cual la Provincia debía considerarse gravemente ofendida. En conclusión, la Diputación debería instar al corregidor a cesar en su empeño de querer hacer 
Cestona en los orígenes del termalismo vasco (1776-1833).

La conformación de un establecimiento de baños en Guipúzcoa

cumplir su arancel hasta su sanción por el Consejo y el posterior pase de la Provincia.

\section{TRIUNFO DE LA LIBRE COMPETENCIA}

Con la denuncia del arancel ante el Consejo, Rafaela Valdivia consiguió que el fiscal pasase este expediente al ministro director superintendente de baños termales 0 a quien nombrase para la dirección de los baños de Cestona, cargo que recaería en Vicente Borja, ministro del Consejo ${ }^{54}$. Este dio a conocer su dictamen a principios de 182955 , compartiendo algunos aspectos del arancel del corregidor de Guipúzcoa y otros no. Por ejemplo, estaba de acuerdo con los precios fijados para los baños y las aguas, pero no así con la imposición de los de las habitaciones, donde debía primar la libertad del propietario para establecer las tarifas que creyese más convenientes. Aunque este sí se vería obligado a anunciar los precios diarios del servicio de hospedería, al igual que Catalina Zubizarreta. Lo que se traduce en libertad de precios y en el anuncio de los mismos. Estaríamos hablando de un claro antecedente de la publicidad de las listas de precios para que el consumidor supiese en todo momento a qué atenerse. También estaba de acuerdo con las normas de orden fijadas por Aynat, extensibles igualmente a la hospedería de Zubizarreta, cuyos huéspedes tendrían el mismo derecho a tomar los baños que los alojados en el balneario. Un derecho de uso extensible no sólo a los bañistas de la casa de Zubizarreta, sino también a todos aquellos alojados en Cestona y Azpeitia o en los caseríos cercanos. Según Borja, ninguno de ellos debía pagar más que quienes pernoctasen en el establecimiento de baños, ya que las tarifas habían de ser iguales para todos. San Millán no tenía el derecho exclusivo para alojar a los bañistas, por lo que la iniciativa de Catalina Zubizarreta era legítima y, como tal, debía ser protegida. Finalmente, en su dictamen se obligaba a los San Millán a pagar 60 ducados al médico titular de Cestona en concepto de complemento de los 400 ducados que se le pagaba y que eran considerados escasos.

No estando de acuerdo Rafaela Valdivia con la resolución de Borja, pocos días después, Peyron solicitaba la aprobación del reglamento de baños establecido por Aberasturij5. El objetivo principal era el aumentar los precios a fin de mantener el negocio a salvo de la amenazadora competencia de la casa de Catalina Zubizarreta, toda vez que habían sido los marqueses de San Millán quienes habian hecho las grandes inversiones en el establecimiento de baños y quienes, por ende, habían conseguido que el termalismo vasco hubiese terminado de despegar. En definitiva, todo ello se podía venir al traste con la competencia ejercida por Zubizarreta, quien ofertaba un hospedaje más barato, pudiendo así atraer a una clientela cada vez mayor, poniendo en la picota el negocio termal de Cestona. Desde luego, tales argumentos eran contundentes, pero no suficientes, por lo que el 2 de mayo de

54 Vicente Borja fue nombrado superintendente de los baños de Guesalaga el 23 de septiembre de 1828.

55 AHN, Fondos de Consejos Suprimidos, 1532, 15, II. a parte, pieza 2. ${ }^{\text {a }}$ corriente, dictamen de Vicente Borja del 5 de enero de 1829, fols. 356-363.

56 AHN, Fondos de Consejos Suprimidos, 1532, 15, II. ${ }^{\mathrm{a}}$ parte, pieza 2. ${ }^{\mathrm{a}}$ corriente, solicitud de Esteban Peyron del ¿10 de enero de 1829?, fols. 396-401.
1829 la Sala de Gobierno del Consejo de Castilla aprobaba "con la calidad de por ahora" el reglamento de baños elaborado por el corregidor de Guipúzcoa ${ }^{57}$. Se mantenían, por tanto, los precios fijados por Aynat, lo que, sin duda, significaba un triunfo provisional de Catalina Zubizarreta, algo que debió suponer una clara contrariedad para los intereses de los marqueses de San Millán y para el inquilino del establecimiento de baños, Duhart.

Ahora bien, la expresión utilizada tenía su intencionalidad, pues todavía no había sido dicha la última palabra en este tema. En efecto, una real provisión de Su Majestad y de los miembros de su Supremo Consejo Real, fechada el 3 de julio de 1830, disponía dos variaciones en el reglamento provisional del corregidor de notable importancia. Una, que los concurrentes sólo se alojasen en la casa de Catalina Zubizarreta o en los caseríos próximos cuando no hubiese sitio en la casa de baños principal. $Y$ dos, que la justicia de la villa de Cestona, oyendo al Ayuntamiento y a la marquesa viuda de San Millán, fijase los precios a pagar por los baños y las aguas, de suerte que, de no haber acuerdo, se comunicase al Supremo Consejo. Como puede comprobarse, los matices introducidos en absoluto eran nimios y establecían novedades importantes. De hecho, semejante provisión suscitó las quejas de la villa de Cestona ante la Provincia, que no estaba de acuerdo con esta modificación, sobre todo, si tenemos en cuenta que algunos de sus vecinos venían ya aprovechándose de que ciertos clientes se alojaban en sus casas y no en la de los San Millán. Una modificación de este calibre era ir en contra de sus intereses. Y así lo debió reconocer la propia Diputación, ya que, a la vez que la villa de Cestona y Catalina Zubizarreta, se dirigió al Consejo quejándose de las nuevas medidas. En este sentido, el propio Lizarzaburu en su informe ya citado había insistido en esta misma idea. Su Majestad entonces accedió a la petición el 25 de noviembre de 1830 , restableciendo el contenido original del arancel del corregidor ${ }^{58}$.

Finalmente, terminó triunfando el ideario liberal. La libertad de competencia, en contra de la exclusividad sostenida por Rafaela Valdivia, había sido uno de los principales argumentos de Zubizarreta, quien vio de esta guisa compensado su esfuerzo. Eso sí, esta vez con la ayuda de la Diputación Foral y del Ayuntamiento de Cestona, que entendieron que la pretensión de Rafaela Valdivia iba en contra de la libre concurrencia. El hecho de no hacer distinción entre los alojados en una u otra casa suponía inclinar la balanza hacia sus intereses, tal como venía reclamando desde hacía varios años. Lo cual nos ha de llevar a una reflexión, basada en el hecho de que parece claro que algo estaba cambiando en la sociedad española de esos años. Si unos lustros antes Joaquín Aguirre Porcel había podido hacer a su antojo en los baños de Cestona sin someterse a ley alguna e incluso viendo incumplirse la real orden de 1804, la cual instaba al corregidor a formar un arancel de precios, la situación ahora ya no parecía la misma. No sólo una ex empleada de los marqueses como Catalina Zubizarreta había logrado sus objetivos, sino que esta vez el corregidor cumplió con su deber de elaborar el reglamento, independientemente de

57 AHN, Fondos de Consejos Suprimidos, 1532, 15, II. ${ }^{a}$ parte, pieza 2. ${ }^{\text {a }}$ corriente, aprobación del reglamento del corregidor de Guipúzcoa del 2 de mayo de 1829 , fols. $406-409$.

58 AGG-GAO, JD IM 1/19/111. 
los intereses de los San Millán. ¿Estaban perdiendo fuerza frente al Consejo de Castilla? Todo parece indicar que sí. La época de Joaquín Aguirre, un hombre más propio del Antiguo Régimen, estaba dando paso a un nuevo periodo alumbrado por el Liberalismo y protagonizado por una burguesía ascendente.

Al margen de esta polémica, se podría decir que la fama de la casa de baños de Guesalaga aumentaba y no es de extrañar, en consecuencia, que en julio de 1830 recibiera a un star de la talla del infante Don Francisco de Paula Antonio, hermano de Fernando VII, con su esposa Luisa Carlota y sus seis hijos ${ }^{59}$. Esta visita de varios miembros de la familia real suponía un auténtico espaldarazo para el establecimiento de San Millán, así como la consolidación de un balneario que no tardaría en atraer a cada vez más visitantes, si bien, como buena parte de los balnearios españoles, se vio seriamente afectado en su actividad con el estallido de la Primera Guerra Carlista, la cual, como es sabido, tuvo uno de sus epicentros fundamentales en las provincias vascas. Cuando el negocio termal vasco tendía a consolidarse, con la existencia no sólo de Cestona, sino también del balneario de Santa Águeda (abierto en 1827), el comienzo de la conflagración supuso un freno considerable, aunque no lo suficientemente grave como para poder echar por tierra una actividad, la termal, que ya había echado sólidas raíces en suelo vasco, configurándose, al menos en el caso de Guipúzcoa, una oferta termal de primer orden durante los años del reinado de Isabel $\left.1\right|^{60}$.

\section{Conclusiones}

El balneario de Cestona constituye la primera iniciativa dentro del termalismo vasco y una de las primeras de la industria termal española. Y no parece casualidad que sus orígenes estén plenamente vinculados a la Real Sociedad Bascongada de los Amigos del País, una institución de carácter ilustrado preocupada por los avances en todas las ciencias experimentales. Que los primeros análisis químicos de las aguas de Guesalaga se desarrollasen en el seno del Seminario Patriótico de Vergara, fundado por la propia Bascongada, resulta de lo más normal. Como también lo es que sus orígenes estén asimismo ligados a personajes vinculados con esta sociedad. Hombres ilustrados que supieron ver en el fomento de las aguas minero-medicinales de Cestona una buena oportunidad al servicio de la humanidad doliente, al tiempo que una nueva fuente de riqueza. En ese sentido, tanto Vicente de Lili como Joaquín Aguirre Porcel pertenecían a esa nobleza rural guipuzcoana, la cual, gracias a sus inquietudes, puso en marcha este tipo de proyectos. En un tiempo, además, en que tanto el Consejo de Castilla como el Real Protomedicato estaban especialmente sensibilizados con el nefasto estado de los veneros españoles. Su deseo de ponerlos en explotación constituyó, sin duda, un claro incentivo para ambos, si bien es verdad que fue finalmente el segundo, el marqués de San Millán, quien consiguió hacerse con las

59 Urquía, 1985, 83. Agradezco a Ignacio Cabrero, director del Gran Hotel Balneario de Cestona, que me haya proporcionado una copia del escrito dirigido desde la Capitanía General de Guipúzcoa al secretario de Estado y del Despacho de la Guerra dando cuenta de esta visita y fechado el 19 de julio de 1830.

60 Larrinaga, 2013. aguas y los baños, fundando el moderno establecimiento de baños de Cestona. A este respecto, se superaba con creces a la primitiva casa de baños de Vicente de Lili, quien, aquejado por falta de numerario, no tuvo más remedio que renunciar a emprender la obra que el Consejo le exigía, vendiendo finalmente su propiedad a San Millán, poniendo entonces fin a la rivalidad que en torno a las aguas se había generado no sólo entre ambos, sino también con la villa de Cestona, que en no pocas ocasiones aspiró a hacerse cargo de las mismas. También aquí los problemas económicos derivados de la crisis de las haciendas locales de finales del siglo XVIII y principios de la siguiente centuria inclinaron la balanza a favor de San Millán, al parecer, el mejor situado económicamente y con amplias influencias en la Corte. No en vano estaríamos hablando de uno de los nobles más importantes de la provincia de Guipúzcoa. Al final, lo cierto es que, gracias a sus inversiones, Cestona fue una realidad para principios del siglo XIX, situándose así en esa primera generación de balnearios modernos en España y con pretensiones de convertirse en uno de los mejores de su clase, algo que, sin duda, consiguió. Todo parece indicar que el contencioso mantenido por sus descendientes con Catalina Zubizarreta, su ex inquilina, no debió influir mayormente en la consecución de este objetivo. Por el contrario, puso a las claras que del negocio termal podían aprovecharse más de una casa de huéspedes, lo que da buena idea de las potencialidades de esta actividad en la zona, así como del carácter emprendedor de sus protagonistas. Porque Vicente de Lili, Joaquín Aguirre, Catalina Zubizarreta o Ramón Mendía (fundador de Santa Águeda) fueron unos auténticos pioneros del negocio termal vasco, sentando las bases de una industria que cogió mucha mayor fuerza durante las décadas centrales y finales del siglo XIX.

\section{BibLIOgRAFía}

Aguado Pintor, A. 2002: "La Isabela, un nuevo Real Sitio para los monarcas del siglo XIX", en Espacio, Tiempo y Forma. Historia del Arte, 15, 229-254.

Alonso Álvarez, L., Lindoso Tato, E. y Vilar Rodríguez, M. 2011: O lecer das augas. Historia dos balnearios de Galicia, 1700-1936. Vigo, Galaxia.

Alonso Álvarez, L., Vilar Rodríguez, M., y Lindoso Tato, E. 2012: El agua bienhechora. El turismo termal en España 1700-1936. Alhama de Granada, Observatorio del Termalismo.

Anduaga, A. 2010: La cadena vasca: educación, tecnología, poder social y rendimiento industrial, 1776-1902. Barcelona, Ediciones del Serbal.

Barriola, I. M. ${ }^{\text {a } 1956: ~ " L a s ~ a g u a s ~ d e ~ C e s t o n a ~ y ~ l o s ~ c a b a l l e r i t o s ~ d e ~ A z c o i-~}$ tia", en Homenaje a D. Joaquín Mendizábal Gortázar. San Sebastián, Museo de San Telmo, 76-82.

Bouza, J. 2000: "La difusión de innovaciones científicas y el desarrollo de la balneoterapia: la incorporación de los procesos de la química", en Scripta Nova. Revista Electrónica de Geografía y Ciencias Sociales, 69, 39 (http://www.ub.ees/geocrit/sn-50.htm).

Boyer, M. 2002: "El turismo en Europa, de la Edad Moderna al siglo XX", en Historia Contemporánea, 25, 13-31.

Chadefaud, M. 1987: Aux origines du tourisme dans les pays de l'Adour. Pau, Université de Pau. 
Cestona en los orígenes del termalismo vasco (1776-1833). La conformación de un establecimiento de baños en Guipúzcoa

Hembry, P. 1990: The English Spa, 1560-1815. A Social History. London, The Athlone Press.

Jovellanos, Gaspar Melchor. 1915: Diarios: 1790-1801. Madrid, Imprenta de los Sucesores de Hernando.

Larrinaga, C. 2013: "Nacimiento y evolución del termalismo vasco durante el siglo XIX. El caso de Guipúzcoa", en Tst. Transportes, Servicios y Telecomunicaciones, 24, 58-84.

Mercado Blanco, J., Herrera Casado, A., Moya Benito, M. J. 2003: Historia de Sacedón. Patrimonio y costumbres. Guadalajara, AACHE Ediciones de Guadalajara.

Otaegui, A. 1991: Guerra y crisis de la hacienda local. Las ventas de bienes comunales y de propios en Guipúzcoa, 1764-1814. San Sebastián, Diputación Foral de Guipúzcoa.

Quesada y Agíus, B. 1878: Apuntes para una monografía sobre las aguas de Cestona. Úbeda, Imprenta de Francisco de P. Gámez.

Rodríguez-Sánchez, J. A. 1992: "Nuevos documentos para la historia de la Hidrología: El marqués de San Millán y la fundación del Balneario de Cestona", en Cuadernos Vascos de Historia de la Medicina, I, 109-125.

Sánchez Ferré, J. 2000: "Historia de los balnearios en España. Arquitectura-patrimonio-sociedad", en López Geta, J. A. y Pinuaga, J. L. (edits.): Panorama actual de las aguas minerales y minero-medicinales en España. Madrid, Instituto Tecnológico Geominero de España, 213-230.

Silván, L. 1953: Los estudios científicos en Vergara a fines del siglo XVIII. San Sebastián, Biblioteca Vascongada de Amigos del País.

Urquía, J. M. 1985: Historia de los balnearios guipuzcoanos. Bilbao, Euskal Medikuntzaren Historia-Mintegia y Medikuntza Historiaren Euskal Elkartea.

Vidal-Abarca, J. 1989: "La nobleza titulada en la Real Sociedad Bascongada de los Amigos del País", en II Seminario de Historia de la Real Sociedad Bascongada de los Amigos del País. San Sebastián, RSBAP, 445-592.

Zeaorrote, P. de. 1822: Investigaciones analíticas y observaciones médicas sobre las aguas de Guesalaga, comúnmente llamadas de Cestona. Bilbao, Felipe Morales y Cía. 